\title{
Morango: uma preocupação alimentar, ambiental e sanitária, monitorado por cromatografia líquida moderna
}

\author{
Daniele Oshita, Isabel Cristina Sales Fontes Jardim* \\ Departamento de Química Analítica, Instituto de Química, Universidade Estadual de Campinas - UNICAMP \\ Cep 13083-970, Campinas, SP, Brasil \\ e-mail:icsfj@iqm.unicamp.br
}

Resumo

A presente revisão tem como objetivo reunir em um único manuscrito informações desde a produção agrícola do morango até os aspectos negativos que podem influenciar e atingir o meio ambiente ou gerarem preocupações com a saúde dos trabalhadores rurais e consumidores que tenham contato direto com o meio ambiente ou que consomem o morango in natura. O morango é uma das culturas que lideram, desde o ano de 2002, o ranking dos alimentos mais contaminados por resíduos de agrotóxicos no Brasil. A cromatografia líquida moderna é uma das técnicas analíticas mais desenvolvidas e empregadas para determinação de resíduos de agrotóxicos em alimentos.

Palavras-chave

CLAE; agrotóxicos; morango.

\section{Strawberry: food, environmental and sanitary concerns, monitored by modern liquid chromatography}

\section{Abstract}

This review aims to present information in a single manuscript initiating with the agricultural production of strawberries and concluding with the negative aspects that influence environment or generate concerns about the health of farm workers and consumers who have direct contact with the environment or, even the consumers of fresh strawberries. Strawberry crops are those that leads, since the year 2002, the ranking of the foods most contaminated with pesticide residues in Brazil. Modern liquid chromatography is one of the most developed analytical techniques and is thus often employed for the determination of pesticide residues in foods.

Keywords

HPLC; pesticides; strawberry. 


\section{Introdução}

A cromatografia líquida de alta eficiência (CLAE) é uma das técnicas analíticas mais desenvolvidas e empregadas na academia, em diversos tipos de pesquisa e em indústrias, nas análises de rotina e de controle de qualidade. A grande aplicabilidade da CLAE para a determinação de resíduos de agrotóxicos em alimentos se justifica por esta ser uma técnica de separação eficaz e, juntamente com um detector adequado, permitir a identificação, quantificação e, quando necessário, a confirmação do analito.

Nos últimos anos, tem-se observado grande crescimento e investimento, pelos órgãos de pesquisas científicas, governamentais e de empresas privadas, nos estudos de resíduos de agrotóxicos em alimentos. Esse interesse na área de resíduos está relacionado com o impacto ambiental que a produção agrícola pode gerar no meio ambiente, atingindo ar, solo e água. Acrescido a isto, os consumidores estão mais conscientes e interessados nas consequências que o consumo de um alimento contaminado pode causar à saúde. Esta contaminação tem origem, muitas vezes, em uma produção agrícola que não segue adequadamente as Boas Práticas Agrícolas (BPA). Além disso, deve-se considerar que a exportação de alimentos ocorre em função da qualidade dos produtos nacionais e das exigências do comércio exterior.

O morango, cada vez mais, vem se destacando por estar presente na lista dos alimentos mais contaminados por resíduos de agrotóxicos no Brasil, por vários anos consecutivos; ter consumo elevado, principalmente in natura, por crianças e adultos; possuir propriedades funcionais diversificadas e por ser bastante usado na culinária. $\mathrm{O}$ estudo de resíduos de agrotóxicos no morango constitui uma preocupação alimentar, ambiental e sanitária, que pode envolver toda a população consumidora ou não e os seres vivos que compartilham o mesmo ambiente da produção agrícola desse fruto ou aqueles para os quais os agrotóxicos foram lixiviados.

\section{Morango e suas propriedades físico-químicas}

As frutas são alimentos essenciais em uma dieta equilibrada e balanceada, pois são fontes importantes de vitaminas e minerais que são nutrientes indispensáveis para uma vida saudável. O morangueiro pertence à família das Rosáceas e ao gênero (Fragaria $\times$ ananassa Duch.); a parte comestível é formada por um receptáculo carnoso e suculento, de coloração vermelha viva, formando um pseudofruto. Os frutos verdadeiros são os aquênios, estruturas diminutas, que contêm as sementes presas ao receptáculo. Este fruto é produzido e apreciado em várias regiões do mundo, sendo uma das espécies de grande evidência e de maior expressão econômica entre as frutas pequenas, por seu alto consumo mun$\operatorname{dial}^{[1-4]}$.

Os consumidores apreciam a coloração, o aroma, o sabor e as propriedades nutritivas do morango, o que aumenta o seu poder de comercialização em muitos países. O maior consumo de morango ocorre in natura, mas pode ser industrializado como geleia, caldas, polpas para sucos, iogurtes e sorvetes ${ }^{[5]}$.

O morango, como alimento, possui 2,3\% de fibras, 92,8\% de água e 39 calorias em 100 gramas de frutos, vitaminas A, B1, B2, B3 e C, elementos minerais como potássio, sódio, cálcio, ferro e fósforo, ácido fólico e também é rico em frutose e sacarose e pobre em carboidratos ${ }^{[6]}$. Quando o morango é consumido numa refeição bem balanceada, há uma reação química que triplica os índices de absorção de ferro presente nos vegetais, ovos e carnes ${ }^{[7]}$. 
O morango possui elevado poder antioxidante, associado aos compostos fenólicos e pigmentos, que são representados pelas antocianinas, metabólitos pertencentes à classe dos flavonoides. A atividade antioxidante das antocianinas provém da sua estrutura química formada por três anéis que possuem ligações duplas conjugadas e por hidroxilas distribuídas ao longo da estrutura, que possibilitam o sequestro de radicais livres, causadores de danos celulares e de doenças degenerativas ${ }^{[8]}$. O morango também contém uma quantidade elevada de ácido elágico, um constituinte com propriedades antimutagênicas e anticancerígenas. Devido à presença dessas variedades de componentes naturais, o morango é capaz de atuar na prevenção e/ou na cura de várias doenças e é considerado antioxidante, anticarciogênico, antineurodegenerativo, anti-inflamatório, diurético, laxativo e previne doenças coronarianas ${ }^{[5,9-11]}$.

\subsection{Dificuldades na pré-colheita, colheita e pós-colheita do morango}

A colheita do morango é uma das operações mais delicadas e importantes de todo o ciclo da cultura, porque os frutos do morangueiro são altamente perecíveis, muito delicados e pouco resistentes em virtude da epiderme delgada, grande porcentagem de água e alto metabolismo. Quando colhidos muito maduros, poderão chegar ao mercado em decomposição e com podridões; ou quando colhidos ainda verdes, terão alta acidez, adstringência e ausência de aroma. Em ambos os casos, o produto possui baixo valor comercial ${ }^{[7,12]}$. Os morangos possuem vida útil curta pós-colheita, devido à rápida deterioração causada por fungos, à elevada taxa respiratória e ao aumento da produção de etileno, mesmo quando armazenados sob refrigeração ${ }^{[2]}$. Esta taxa elevada de perecibilidade requer cuidados quanto à embalagem, transporte e conservação.
Existem vários tratamentos ${ }^{[13]}$ que podem ser aplicados na conservação dos morangos in natura: (i) a imersão em uma solução contendo cloreto de cálcio em até $1 \%$, para manter a firmeza e aumentar o conteúdo de cálcio e de sólidos solúveis; (ii) o processo de irradiação, ${ }^{[2]}$ no qual a exposição a baixas doses de radiação pode diminuir a velocidade de amadurecimento e de envelhecimento de frutas e vegetais; (iii) a manutenção dos morangos em embalagens, por meio do aumento da espessura do filme que diminui as trocas gasosas, e com concentrações elevadas de $\mathrm{CO}_{2}$ ocasionam aumento ou a manutenção da firmeza do morango, reduzem a incidência de fungos, diminuem as taxas respiratórias e a produção de etileno; (iv) o uso da refrigeração associado a um controle da atmosfera que é uma técnica promissora e de baixo custo que minimiza as perdas de qualidade e peso, e a degradação por micro-organismos. Porém, esses frutos processados minimamente podem apresentar menor teor de antocianinas que os mantidos em atmosfera ambiente ${ }^{[14,15]}$. Outra maneira de obter um processamento mínimo do morango é a sanificação que contribui para a redução de micro-organismos alteradores e melhora a condição higiênico-sanitária dos alimentos. Encontram-se disponíveis para a sanificação compostos à base de cloro, amplamente utilizados em função do custo, da disponibilidade e maior atividade germicida; e sanificantes alternativos como o peróxido de hidrogênio ${ }^{[16,17]}$.

As dificuldades existentes na etapa de produção ocasionam desde perdas nutritivas até econômicas, pois os consumidores não compram frutos com um aspecto físico ruim.

\subsection{Produção agrícola do morango}

O Brasil, depois da China e da Índia, é o $3^{\circ}$ maior produtor de frutas do mundo, que é uma das atividades agrícolas mais importantes para o 
País. A maior porcentagem da produção é destinada para o consumo interno e apenas, aproximadamente, $2 \%$ da produção é exportada ${ }^{[18,19]}$. Anualmente, desde a última década, a produção nacional do morango tem aumentado em média $6,3 \%$, em comparação aos 3,7\% para outras frutas e vegetais nesse mesmo período $^{[20] .}$

Os seis principais países em produção e produtividade de morango são, respectivamente, Estados Unidos (740.800 t; $41 \mathrm{t} \mathrm{ha}^{-1}$ ), Espanha (306.000 t; $38 \mathrm{t} \mathrm{ha}^{-1}$ ), Japão (200.000 t; $\left.25 \mathrm{t} \mathrm{ha}^{-1}\right)$, Itália (172.600 t; 23,5 $\left.\mathrm{t} \mathrm{ha}^{-1}\right)$, Coreia do Sul (151.200 t; 20,5 t ha-1) e Polônia (145.000 t; $\left.3 \mathrm{t} \mathrm{ha}^{-1}\right)$. A produção brasileira alcançou um volume superior a $90.000 \mathrm{t}$ em 1999 e a produtividade média da cultura no Brasil é de 25 tha ${ }^{-15]}$. Embora o Brasil não figure entre os maiores produtores, sua produção vem crescendo, concentrando-se principalmente nos Estados de Minas Gerais, Rio Grande do Sul, São Paulo, Paraná e Distrito Federal. Os três primeiros Estados produzem aproximadamente $80 \%$ do morango brasileiro $^{[1,5,6,8,21,22]}$.

No Brasil, a produção de morango encontra-se difundida em regiões de clima temperado e subtropical, que se destacam pela alta rentabilidade por área e demanda intensa de mão de obra $^{[1,23]}$. A produção é quase toda voltada para o mercado doméstico, sendo cerca de $70 \%$ destinada ao consumo in natura e $30 \%$ industrializada de diversas formas ${ }^{[24]}$.

A produção do morango tem tendência crescente devido ao alto consumo, porém tem deparado com muitas dificuldades, sendo as principais: incidência de pragas e doenças (28\%); aquisição de mudas (24\%); custo de embalagens (24\%); necessidade de mão de obra (19\%); e custos de produção elevados $(5 \%)^{[25]}$.

A sazonalidade da produção de morangos no Brasil é um dos principais problemas da cultura, pois esses pseudofrutos em época de entressafra têm seu preço elevado. Embora cresçam melhor em regiões mais frias, os morangueiros podem se desenvolver bem em clima quente e seco. Segundo Ronque (apud Tessarioli Neto et al.) ${ }^{[26]}$, a produção do morango é dependente de fatores climáticos, sendo de maior expressão a temperatura e o fotoperiodismo, e de menor intensidade a estiagem, chuvas excessivas, umidade e intensidade da luz. Devido a esses empecilhos, há grande busca por novas e melhores técnicas de cultivo e tipo de cultivar, para aumentar a produtividade e a lucratividade dessa cultura. Os métodos de cultivos utilizados são: convencional, orgânico e hidropônico, a céu aberto ou em cultivo protegido $\mathrm{o}^{[1,3]}$.

O cultivo em ambiente protegido ocorre com controle de temperatura e umidade, proteção contra ventos, granizos, chuvas e geadas, e resulta em menor incidência de doenças fúngicas e bacterianas, devido à redução da umidade foliar $^{[27]}$. A hidroponia surgiu como uma técnica altamente racional, na qual se consegue a otimização do uso de água, do espaço, do tempo e dos nutrientes. Essa alternativa pode sanar problemas como, escassez de mão de obra, qualidade dos pseudofrutos e baixa lucratividade e promover o aumento da produção e qualidade dos fru$\operatorname{tos}^{[26,28,29]}$.

Uma alternativa para manter a qualidade do alimento e amenizar os impactos ambientais é a Produção Integrada (PI), que é um sistema que está entre a produção convencional e orgânica, gerando alimentos de qualidade, mediante o uso de recursos naturais e métodos ecologicamente corretos e seguros, nos quais se minimizam a aplicação de insumos e contaminantes para assegurar a sustentabilidade ambiental, segurança alimentar e viabilidade econômica ${ }^{[30]}$. Na PI, o uso de agrotóxicos é restrito a acaricidas seletivos ou específicos, com baixa persistência, que não deixem resíduos nos frutos, e a manutenção 
da cultura pode ser realizada pelo controle químico, biológico ou cultural, que reduzem a ação das pragas e, consequentemente, diminuem a quantidade de agrotóxicos aplicados no campo.

O cultivo sem solo, em ambiente protegido, sobre bancadas ou suportes acima do nível do solo, é outra alternativa para amenizar os graves problemas na produção do morango ${ }^{[31]}$. Essa técnica diminui ou elimina os problemas sanitários de contaminação dos solos por patógenos, reduz os impactos ambientais, aumenta a produtividade e a qualidade das frutas e diminui os custos na plantação. O cultivo do morangueiro sem solo está bem difundido na Europa, porém, no Brasil, ainda é incipiente por falta de pesquisas que permitam a sua adaptação nas regiões produtivas do País ${ }^{[5]}$.

Outro parâmetro que pode influenciar a produção são os cátions disponíveis no solo, sendo que o potássio age no controle das reações de síntese, enquanto o cálcio influencia a estrutura e a resistência da parede celular ${ }^{[32]}$.

Outra dificuldade na produção do morango é a obtenção das mudas, que está diretamente relacionada com a produtividade e a qualidade da fruta produzida, pois representa o ponto de partida. Em sua maioria, as mudas produzidas no País não atingem o padrão de certificação. Consequentemente, mais de $80 \%$ das mudas utilizadas no Rio Grande do Sul são importadas do Chile e da Argentina ${ }^{[1]}$.

O sistema de produção deve priorizar a utilização de métodos naturais, agrícolas, biológicos e biotecnológicos de controle de pragas e doenças, concomitantemente com a utilização de mudas sadias ou certificadas; emprego de técnicas adequadas como irrigação, adubação e manejo dos túneis; limpeza do entorno das áreas de produção e adoção de técnicas que conservam o solo ${ }^{[7]}$. Estas práticas reduzem a aplicação de agrotóxicos e, consequentemente, contribuem para preservação ambiental e segurança alimentar.

\section{Resíduos de agrotóxicos}

Na cultura do morango é grande a incidência de doenças e pragas que atingem as várias fases do ciclo da cultura, desde a muda recém-plantada até os frutos na fase final de produção. Para tentar contornar esses problemas e amenizar os prejuízos, utilizam-se agrotóxicos. Consequentemente, a cultura do morango necessita de um controle rigoroso que é realizado por meio do monitoramento de resíduos de agrotóxicos.

Os aspectos negativos da produção do morango podem ser verificados pelos dados e constatações da Agência Nacional de Vigilância Sanitária (ANVISA), ${ }^{[33]}$ através do Programa de Análise de Resíduos de Agrotóxicos em Alimentos (PARA). Baseado nos relatórios de atividades divulgados em dezembro de 2011, o morango, juntamente com o pimentão e o pepino, lidera o ranking dos alimentos mais contaminados com resíduos de agrotóxicos no Brasil. No caso do morango, o percentual de amostras irregulares foi de $63,4 \%$, sendo que os problemas detectados nas análises dessas amostras foram os teores de resíduos de agrotóxicos acima do Limite Máximo de Resíduos (LMR) permitido e a detecção de agrotóxicos não autorizados para esta cultura. Esse fato na cultura do morango tem ocorrido desde 2002, e vem apresentando os resultados insatisfatórios mais elevados nas análises de resíduos de agrotóxicos na categoria de frutas.

\subsection{Breve histórico dos agrotóxicos}

Há mais de dois mil anos, os agricultores utilizavam substâncias que preveniam os danos causados por pragas, sendo uma das primeiras o enxofre. No século XV, utilizavam outras sustâncias tóxicas como arsênio, mercúrio e chumbo 
e no século XVII começaram a empregar o sulfato de nicotina que era extraído das folhas de tabaco $^{[34]}$.

No Brasil, o uso de agrotóxicos industrializados já tem mais de meio século e uma das primeiras substâncias aplicadas nas lavouras foi o diclorodifeniltricloroetano (DDT).

Em 1985, a Portaria no 329 de 2 de Setembro de $1985^{[35]}$ proibiu, em todo o território nacional, a comercialização, o uso e a distribuição de produtos organoclorados destinados à agropecuária, exceto, para uso como iscas formicidas e de cupimicidas, combate a vetores de agentes etiológicos de moléstias, em uso emergencial na agricultura e na preservação de madeiras. O DDT, como todos os demais organoclorados, foi banido, tendo em vista seus efeitos nocivos baseados na neurotoxicidade, no aumento de câncer de mama em mulheres, em alterações causadas pelos efeitos estrogênicos, além dos problemas ambientais, como rápida absorção e bioconcentração nos organismos, redução da capacidade reprodutiva das aves e estabilidade alta à decomposição ou à degradação ambiental ${ }^{[36-38]}$.

A busca por agrotóxicos menos persistentes no meio ambiente promoveu o uso dos organofosforados e carbamatos ${ }^{[37]}$.

A classificação dos agrotóxicos constitui tema de controvérsia, pois várias denominações têm sido empregadas para designar sua ação ou organismo alvo (defensivos agrícolas, biocidas, pesticidas, praguicidas, produtos fitossanitários e agrotóxicos). No Brasil, a Lei Federal n 7.802 de 11 de julho de $1989^{[39]}$, conhecida como "Lei de Agrotóxicos", regulamentada pelo Decreto $\mathrm{n}^{\mathrm{o}} 4.074$ de 4 de Janeiro de $2002^{[40]}$, adota e define o termo "agrotóxico" para ser utilizado em todos os casos, substituindo os demais termos supra$\operatorname{citados}^{[38]}$. A Agência de Proteção Ambiental $(\mathrm{EPA})^{[41]}$ define o termo agrotóxico como sendo uma substância química ou mistura de substân- cias utilizadas para prevenir, destruir, repelir ou mitigar qualquer praga, ou mesmo, para regular, desfolhar e dessecar plantas.

Os agrotóxicos podem ser classificados quanto a: Finalidade (acaricida, aficida, formicida, fungicida, herbicida, inseticida, larvicida, ovicida, raticida, entre outros); Modo de Ação (ingestão, contato, microbiano e fumegante); Origem, provenientes de compostos orgânicos ou inorgânicos, de vegetais, bactérias ou fungos $^{[38,42,43]}$. Os agrotóxicos inorgânicos foram muito utilizados no passado, porém, atualmente não representam mais que $10 \%$ do uso total, enquanto os agrotóxicos orgânicos constituem o maior grupo compreendendo os de origem vegetal e os organossintéticos ${ }^{[44]}$.

Outra maneira de classificar os agrotóxicos é segundo as classes toxicológicas, em função da dose letal mediana (DL50) ${ }^{[45]}$. Dependendo da toxicidade do agrotóxico, a cor dos rótulos das embalagens ou as numerações podem variar: $\mathrm{I}=$ rótulo vermelho (extremamente tóxico); $\mathrm{II}=$ rótulo amarelo (altamente tóxico); III = rótulo azul (medianamente tóxico); e IV = rótulo verde (pouco tóxico) $)^{[7,46]}$.

Outra classificação refere-se ao registro de propriedade industrial: produtos sob Proteção de Patentes ou Genéricos ${ }^{[47]}$. Segundo a Associação Brasileira dos Defensivos Genéricos $(\mathrm{AENDA})^{[48]}$, esse mercado representa mais de $70 \%$ em volume e $50 \%$ do valor negociado no mundo.

Os agrotóxicos somente podem ser utilizados no Brasil se estiverem registrados em um órgão federal competente. Segundo o Decreto $\mathrm{n}^{\circ} 4.074$ de 4 de janeiro de $2002^{[40]}$, os três órgãos competentes para o registro de agrotóxicos são: Ministério da Saúde (MS), Ministério da Agricultura, Pecuária e Abastecimento (MAPA) e Ministério do Meio Ambiente, através do IBAMA. 


\subsubsection{Produção econômica dos agrotóxicos}

Segundo dados fornecidos pelo Sindicato Nacional da Indústria de Produção para Defesa Agrícola (SINDAG) ${ }^{[49]}$, no período de janeiro a julho de 2011, os inseticidas lideraram em crescimento em relação ao mesmo período em 2010, enquanto os herbicidas e fungicidas tiveram um decréscimo.

Tal crescimento leva à utilização de maiores quantidades de agrotóxicos, gerando preocupação com os alimentos consumidos em grande quantidade e in natura ${ }^{[34]}$. É importante destacar que menos de $0,1 \%$ dos agrotóxicos que são aplicados atingem o alvo, enquanto o restante pode alcançar outros ambientes, como as águas subterrâneas e superficiais, solo e $\operatorname{ar}^{[50]}$.

Os dados disponibilizados pela Associação Brasileira das Indústrias de Química Fina, Biotecnologia e suas Especialidades (ABIFINA) ${ }^{\text {[51] }}$ mostram que o saldo comercial brasileiro entre 2005 e 2010 foi negativo, indicando que a importação de agrotóxicos superou a exportação. Porém, apesar deste cenário, o mercado de agrotóxicos teve um faturamento alto, perdendo apenas para o de medicamentos.

Estatísticas revelam que cada brasileiro consome em média 5,2 L de agrotóxicos por ano, e que, desde 2008, o Brasil tornou-se o maior consumidor mundial de agrotóxicos ${ }^{[52,53]}$.

\subsubsection{Legislação alimentar dos agrotóxicos}

O estudo da avaliação dos riscos crônicos da ingestão de agrotóxicos é um processo no qual a exposição humana a um dado composto por meio de dieta é comparada a um parâmetro toxicologicamente seguro. Em geral, os governos conduzem estudos de avaliação de risco durante o processo de registro do agrotóxico e seus resultados podem influenciar no estabelecimento de LMR permitidos e restringir o uso em algumas culturas. No âmbito internacional, os estudos são conduzidos pela Reunião Conjunta de Peritos em Resíduos de Agrotóxicos da Organização para Alimentação e Agricultura (FAO) e Organização Mundial de Saúde (OMS), e os resultados são posteriormente encaminhados ao Comitê do Codex Alimentarius para avaliação pelos Governos membros ${ }^{[43,54,55] \text {. }}$

O LMR (Limite Máximo de Resíduos) é estabelecido pela legislação federal de cada país, e a Legislação Brasileira, por meio da Anvisa, define este limite como, a quantidade máxima de resíduos de agrotóxico legalmente aceita no alimento, em decorrência da aplicação adequada numa fase específica, desde sua produção até o consumo. O objetivo principal do LMR é garantir que a população, ao consumir diariamente produtos, cujos níveis de agrotóxicos estejam dentro dos limites estabelecidos, não deverá, segundo os conhecimentos científicos atuais, ter qualquer problema de saúde. A legislação também estabelece o intervalo de segurança de cada ingrediente ativo de agrotóxico para cada cultura agrícola ${ }^{[56]}$.

O PARA foi iniciado em 2001 e é coordenado pela Anvisa, em conjunto com os órgãos de vigilância sanitária de 25 Estados participantes e do Distrito Federal. O objetivo é prevenir agravos à saúde da população pela exposição aos agrotóxicos através dos alimentos, implantando assim, em nível nacional, um serviço para monitorar continuamente os níveis de resíduos de agrotóxicos nos alimentos que chegam à mesa do consumidor e adotar medidas de controle ${ }^{[57]}$. O PARA teve um crescimento ao longo dos anos, que pode ser verificado principalmente pelo número de culturas e agrotóxicos monitorados, respectivamente: 2007 (9 e 104), 2008 (17 e 167) e 2009 ( 20 e 234$)^{[58]}$. 
Tabela 1 Porcentagem de amostras de morango insatisfatórias.

\begin{tabular}{cccccccccc}
\hline Ano & 2002 & 2003 & 2004 & 2005 & 2006 & $\mathbf{2 0 0 7}$ & $\mathbf{2 0 0 8}$ & $\mathbf{2 0 0 9}$ & $\mathbf{2 0 1 0}$ \\
\hline$\%$ & 46,03 & 54,55 & 39,07 & $\mathrm{~N}$ & 37,68 & 43,62 & 36,05 & 50,80 & 63,4 \\
\hline N: análises não realizadas. Os resultados referem-se aos Estados: AC, BA, DF, ES, GO, MG, MS, PA, PE, PR, RJ, RS, SC, SE, \\
TO (entre os anos de 2002 a 2008); 25 estados e DF (2009 e 2010).
\end{tabular}

A Tabela $1^{[33,57,58]}$ mostra a porcentagem de amostras de morango insatisfatórias entre 2002 e 2010. Esses resultados referem-se às amostras que apresentaram ingredientes ativos (IA) acima do LMR permitidos ou resíduos de IA não autorizados para a cultura. Através destes resultados observa-se que a utilização de agrotóxicos é muito intensa, caracterizando o índice crescente de irregularidades na produção do morango. Destaca-se que o maior consumo do fruto ocorre in natura, o que é um benefício para os consumidores, por ingerirem alimentos frescos, com todas as propriedades nutricionais e sem conservantes. Porém, o fruto pode conter resíduos de agrotóxicos em níveis elevados, principalmente se uma boa lavagem não tiver sido efetuada ou se o intervalo entre o tempo de aplicação do agrotóxico e de consumo for menor que o recomendado, trazendo malefícios aos consumidores.

$\mathrm{Na}$ última década, o estabelecimento e a regulamentação de LMR têm se tornado mais frequentes, porém existe uma grande dificuldade de harmonização com os valores estipulados pelo Codex Alimentarius. Estas discrepâncias estão relacionadas com vários fatores como, condições edafoclimáticas que são oriundas do meio ambiente e influenciam os solos; pragas presentes no ambiente; dose e forma de aplicação; intervalo de segurança proposto e diferenças nos períodos de colheita, comercialização ou consumo em que se avalia a quantidade de resíduo de agrotóxico ${ }^{[59]}$.

\subsubsection{Emprego de agrotóxicos na cultura do morango}

Diversos fungos, bactérias e vírus atacam o morangueiro destruindo folhas, caules, frutos e raízes. As medidas gerais de controle das doenças são principalmente as preventivas e o uso de mudas sadias. As pragas que destroem o morangueiro são ácaros, insetos (broca-dos-frutos, grilos, pulgões, lagarta-rosca, etc.), nematoides, lesmas e caracóis ${ }^{[7]}$.

Os ácaros são considerados as pragas primárias que causam os maiores danos e prejuízos à cultura do morangueiro, podendo reduzir a produção do morango em até $80 \%$. O seu controle é difícil, pois as colheitas são realizadas diariamente e o fruto é consumido in natura, requerendo a aplicação de acaricidas que possuem um período curto de carência e baixa toxicidade ${ }^{[30,60]}$.

Outro patógeno que prejudica o cultivo do morangueiro é o Colletotrichum acutatum, principal agente da antracnose no morangueiro, que se manifesta pela flor-preta, na qual ocorre a necrose progressiva dos pedúnculos e demais partes dos órgãos florais e culmina com a secagem e morte das flores. Essa é considerada a principal doença da cultura do morangueiro, podendo causar perdas que variam entre $30 \mathrm{e}$ $68 \%{ }^{[61,62]}$. Segundo Kososki et al. ${ }^{[63]}$ aplicações de fungicidas, especialmente de procloráz, garantem maior produção de frutos e menor ocorrência da doença em flores. Entretanto, de modo geral, a incidência da doença em todos os tratamentos é muito alta, mostrando que o controle químico isoladamente pode não ser um método eficiente 
para o manejo da flor-preta, apontando para a necessidade de investigação de outras estratégias de controle da antracnose.

Quando as medidas preventivas e biológicas de controle não são eficientes, recomenda-se a utilização do Controle Químico. Neste contexto, podem ser aplicados na cultura do morangueiro acaricidas registrados, observando-se as doses e os períodos de carência, e deve-se controlar primeiramente os focos de ácaros e, se necessário, toda a lavoura, além de variar os acaricidas com diferentes modos de ação ${ }^{[7]}$.

\subsection{Aspectos negativos dos agrotóxicos}

O uso de agrotóxicos tem sido muito eficaz na redução de infestações de pragas e, consequentemente, para aumentar a produtividade agrícola e a qualidade do produto. No entanto, ao longo do tempo, as pragas alvo têm desenvolvido resistência aos agrotóxicos, acarretando o crescimento das suas populações, o que requer aumento na quantidade ou número de aplicações dos agrotóxicos ${ }^{[64]}$. Dessa forma, uma opção inicial considerada eficiente pode gerar problemas sérios no futuro.

Alguns agrotóxicos e seus metabólitos são considerados problemáticos por serem persistentes e bioacumulativos ${ }^{[65,66]}$. Segundo Schwarzenbach et al., ${ }^{[67]}$ a maioria dos agrotóxicos possuem alta hidrofobicidade e baixa reatividade no meio ambiente, que são as características responsáveis pela tendência em se acumularem ou bioconcentrarem nos tecidos dos organismos vivos.

\subsubsection{Problemas sanitários dos trabalhadores rurais e segurança alimentar dos consumidores}

A intoxicação por agrotóxicos é um problema de saúde pública grave, principalmente nos países em desenvolvimento e nos emergentes. Um dos fatores relacionados com a grande incidência de intoxicações por agrotóxicos é a facilidade de acesso e o número elevado de produtos formulados com essas substâncias, de uso tanto na agricultura como doméstico ${ }^{[68.69]}$.

Os agrotóxicos são potencialmente tóxicos ao homem, podendo causar efeitos adversos ao sistema nervoso central e periférico, ter ação imunodepressora ou ser cancerígenos, mimetizadores de hormônios, entre outros ${ }^{[65,70]}$. A contaminação dos alimentos por resíduos de agrotóxicos pode vir de uma aplicação direta em uma das fases da produção da cultura, do transporte ou do armazenamento ${ }^{[71]}$.

Outro fator preocupante é a contaminação ocupacional que pode ser imediata ${ }^{[34]}$ e pode trazer comprometimentos à saúde que variam em função do estado nutricional, idade e sexo do indivíduo. Existem dois tipos principais de intoxicações por agrotóxicos: a Intoxicação Aguda, na qual os sintomas surgem rapidamente, de forma leve, moderada ou grave, dependendo do tempo de exposição e da toxicidade dos agrotóxicos, e é caracterizada por fraqueza, vômitos, convulsões, contrações musculares, dores de cabeça, dificuldade respiratória, sangramento nasal; e a Intoxicação Crônica, que surge tardiamente, em função de exposições repetidas e gera danos, na maioria das vezes, irreversíveis ${ }^{[38,72]}$.

As principais fontes de intoxicações dos trabalhadores rurais são: falta do uso de vestimenta protetora; despreparo; falta de conhecimento dos perigos causados pelos agrotóxicos; ausência de recursos alternativos para o controle das pragas; indução ao uso excessivo, incentivado por vendedores e propagandas, com o intuito de garantir maior eficiência; condições precárias do trabalhador, como baixa escolaridade, ${ }^{[73]}$ impedindo a leitura das recomendações que constam nas embalagens e falta de acesso às informações sobre os perigos gerados pelo contato com os agrotóxicos, moradias inadequadas, difícil 
acesso ao tratamento de saúde ${ }^{[74]}$ e proximidade das residências com o campo de aplicação dos $\operatorname{agrotóxicos}^{[70]}$.

Frutas e vegetais com resíduos de agrotóxicos acima dos LMR causam grandes prejuízos aos produtores rurais, pois são proibidas de entrarem em mercados externos que possuem uma legislação controlada e rigorosa. Além das perdas econômicas, o fator mais preocupante está relacionado com a falta de segurança alimentar dos consumidores.

Devido às exigências cada vez mais rigorosas do comércio nacional e internacional em relação aos produtos agropecuários, a necessidade de implementação da PI tornou-se uma realidade. Este sistema emprega tecnologias que permitem o controle efetivo do sistema produtivo agropecuário, por meio do monitoramento de todas as etapas, desde a aquisição dos insumos até a oferta ao consumidor ${ }^{[75]}$.

A adoção do sistema de PI evoluiu em curto espaço de tempo, sendo que, no Brasil, as atividades da Produção Integrada de Frutas (PIF) tiveram início entre 1998 e 1999. No estágio atual, o Sistema PIF já atingiu a consolidação em 18 culturas, sendo que o morango ingressou em 03/04/2008 ${ }^{[76]}$. A Produção Integrada do Morango (PIMo) surgiu em função da conscientização dos produtores sobre a necessidade de se adaptarem aos novos princípios e se qualificarem, a fim de poderem competir no mercado internacional ${ }^{[24]}$.

\subsubsection{Impacto ambiental}

Os agrotóxicos possuem vários caminhos que podem gerar rotas de contaminação no ar, solo, água e lençol freático. Os agrotóxicos, quando aplicados diretamente no solo, podem ser degradados por via química, fotólise ou micro-organismos, produzindo metabólitos ou compostos mais simples. Entretanto, as subs- tâncias com alta persistência ou baixa taxa de degradação podem permanecer no ambiente sem sofrerem qualquer alteração e podem ser adsorvidas pelas plantas ou nas partículas do solo, e serem, posteriormente, dessorvidas e lixiviadas, pela presença das chuvas ou dos ventos. Os agrotóxicos podem ser transportados para regiões distantes das de aplicação, ou atingirem as águas superficiais ou percolarem para os lençóis subterrâneos. Nos ambientes aquáticos, os agrotóxicos podem sofrer adsorção ou dessorção nas partículas dos sedimentos, serem degradados por via química, biológica ou fotólise, ou serem volatilizados. $\mathrm{Na}$ atmosfera, o transporte depende das propriedades dos agrotóxicos (solubilidade, pressão de vapor, coeficiente de partição octanol/água, coeficiente de adsorção à matéria orgânica do solo, tempo de meia-vida, constante de ionização, entre outros); condições ambientais (clima, textura e conteúdo de água no solo); topografia e práticas de manejo (tipo de cultura e método de aplicação dos agrotóxicos ${ }^{[42,50,77-80]}$.

O comportamento de agrotóxicos no ambiente deve ser diferente em clima temperado e tropical. Alguns dados experimentais sugerem que as taxas de degradação devem ser mais altas em países tropicais devido às temperaturas e às radiações mais elevadas, que também causam aumento na toxicidade em função da maior volatilização ${ }^{[81]}$.

Um fenômeno ecológico chamado de biomagnificação, no qual ocorre acumulação de agrotóxicos ao longo da cadeia alimentar, leva a um aumento da concentração de uma determinada substância com o aumento do nível trófico. Mesmo em concentrações baixas, os agrotóxicos representam riscos para algumas espécies de organismos aquáticos que podem concentrar estes produtos até 1000 vezes $^{[82]}$. 
Dessa forma, os agricultores devem conservar os recursos naturais, para evitar a contaminação de seres humanos e vivos, e manter o equilíbrio ecológico através da redução de aplicação dos agrotóxicos nas culturas.

\subsection{Produtos orgânicos no Brasil}

A Agricultura Orgânica (AO) é um processo produtivo que emprega um mínimo de insumos externos, porém esta prática não garante a ausência total de resíduos, devido à existência de contaminação ambiental. Ela assegura o fornecimento de alimentos orgânicos saudáveis, mais saborosos e de maior durabilidade, pois apresentam maior resistência ao ataque de micro-organismos. Por não utilizar agrotóxicos e empregar sistema de manejo mínimo, preserva o meio ambiente e assegura a estrutura e fertilidade dos solos, evitando erosões e degradação, contribuindo assim para promover e restaurar a biodiversidade local. Por esse conjunto de fatores, a agricultura orgânica viabiliza a sustentabilidade da agricultura familiar e amplia a capacidade dos ecossistemas locais em prestar serviços ambientais a toda a comunidade do entorno, contribuindo para redução do aquecimento global ${ }^{[83,84]}$. Alguns procedimentos da AO são: uso da adubação verde ou orgânica; minhocultura; manejo da vegetação nativa, rotação de culturas, cultivos protegidos e uso racional da água de irrigação.

No Brasil, a AO possui sua legislação estabelecida pelo Decreto 6.323 de 27 de dezembro de $2007^{[85]}$, que regulamenta a Lei $\mathrm{n}^{\circ} 10.831$ de 23 de dezembro de $2003^{[86]}$. Segundo esta legislação a $\mathrm{AO}$ engloba todas as diferentes correntes de agricultura alternativa ou sustentável ou ecológica. As primeiras correntes da $\mathrm{AO}$ foram: Agricultura Biodinâmica; Agricultura Orgânica; Agricultura Organobiológica e Agricultura Natural ${ }^{[87,88]}$. Aproximadamente $90 \%$ da produção orgânica nacional de banana, soja e café é exportada como matéria-prima, principalmente para os Estados Unidos, União Europeia e Japão. O Brasil também se destaca na exportação de suco de laranja e açúcar orgânico ${ }^{[87]}$.

Krolow et al. ${ }^{[89]}$ avaliaram os aspectos físicos e químicos do morango cv. cultivado de maneira orgânica e convencional. Os resultados mostraram que os morangos cultivados pelo sistema de $\mathrm{AO}$ apresentaram maiores diferenças percentuais para os teores de antocianinas, sólidos solúveis totais e razão de sólidos solúveis totais/acidez total titulável (SST/ATT), que foram de 106,1, 16,1 e $24,3 \%$, respectivamente, e superiores ao sistema convencional. O principal aspecto negativo da $\mathrm{AO}$ foi à redução de $8,4 \%$ no teor de ácido ascórbico em relação ao convencional. Porém, é importante destacar que não somente o sistema de produção influencia nestes índices, mas o ponto de maturação em que a fruta é colhida, haja vista que os produtores tendem a colhê-las um pouco verdes para que resistam até o momento de comercialização.

A procura por alimentos orgânicos é crescente devido aos benefícios já citados, contudo, um dos entraves à expansão deste segmento é o preço que é superior aos dos produtos de cultivo convencional $^{[90,91]}$.

\section{Métodos analíticos de preparo de amostra e de determinação de resíduos de agrotóxicos em amostras de morango}

\subsection{Técnicas de preparo de amostras para extração de resíduos de agrotóxicos}

A determinação de um analito numa amostra é caracterizada por três etapas principais: 1) amostragem, que deve ser representativa de um todo; 2) preparo de amostra, destinada a 
extrair, isolar e/ou concentrar o analito e/ou eliminar os interferentes; 3 ) análise da amostra, separação, identificação e quantificação dos analitos, e, caso necessário, confirmação do resultado para uma análise mais segura ${ }^{[92,93]}$.

Dentre as etapas analíticas empregadas na determinação de multirresíduos de agrotóxicos, a extração dos analitos é considerada uma das mais críticas e importantes, uma vez que engloba procedimentos laboriosos que demandam tempo, custo elevado e geram grandes quantidades de resíduos tóxicos ${ }^{[94-97]}$. Outras adversidades a serem superadas nesta etapa é a extração simultânea de compostos com propriedades físico-químicas diferentes, em baixa concentração e em diferentes matrizes.

A análise de resíduos de agrotóxicos teve início na década de 60 , com determinações de organoclorados; na década de 70 foram introduzidas mudanças para ampliar o intervalo de polaridade dos compostos analisados, que se estenderam para os organofosforados e nitrogenados; e nas décadas posteriores, começaram a surgir preocupações com a utilização dos solventes clorados e com a quantidade de resíduos gerados na etapa de extração, exigindo mudanças nas técnicas de preparo de amostra ${ }^{[97-99]}$.

Numerosas técnicas de extração de agrotóxicos em frutas e vegetais, principalmente em morangos, com determinação por cromatografia líquida (CL) ou gasosa (CG) têm sido empregadas. Entre estas técnicas pode-se destacar: o particionamento de solventes (extração líquido-líquido), extração sólido-líquido (Solid Liquid Extration - SLE) ${ }^{[96,100-103]}$, extração assistida por micro-ondas (Microwave Assisted Extraction - MAE) $)^{[104-106]}$, extração em fase sólida (Solid-Phase Extraction - SPE $)^{[106-111]}$, microextração em fase sólida (Solid-Phase Microextraction - SPME $)^{[104,112-114]}$, dispersão da matriz em fase sólida (Matrix Solid-Phase
Dispersion - MSPD) $)^{[103,115,116]}$, extração líquida pressurizada (Pressurized Liquid Extraction PLE) $)^{[117-119]}$, e extração sortiva em barras de agitação (Stir Bar Sorptive Extraction - SBSE) $)^{[120,121]}$.

Existem várias técnicas de preparo de amostras para alimentos, porém os parâmetros principais que um analista deve levar em consideração para optar por uma técnica de extração são: número e classe de agrotóxicos, limite de quantificação, tipo de amostra e teor de gordura ${ }^{[122]}$. Os métodos de preparo de amostras apresentam vantagens e desvantagens que vão depender: do volume de solvente, extração de coextrativos, uso de solventes não clorados, quantidade de amostra, extração específica ou seletiva, manual ou automatizada, on-line ou off-line, facilidade de acoplamento para determinação por CL ou CG, entre outras.

Em 2003, Anastassiades et al. ${ }^{[99]}$ com o objetivo de superar as limitações práticas dos métodos de extração de multirresíduos de agrotóxicos, introduziram o método QuEChERS (Quick, Easy, Cheap, Effective, Rugged and Safe), no qual o processo de extração consiste de duas etapas: extração por solvente orgânico, com adição de sais para efeito salting out e secante, e clean-up dispersivo. Esse método tem como vantagens ser rápido, fácil, econômico, efetivo, robusto, seguro e compatível com CG e CL ${ }^{[123-125]}$.

Dependendo das características físico-químicas dos analitos e da matriz, podem ser introduzidas modificações no método QuEChERS Original (2003), como mudanças de pH pela adição de diferentes tipos de tampão, emprego de diferentes solventes orgânicos, acetonitrila, acetato de etila e acetona, e utilização de diversos tipos de sorventes na etapa de clean-up.

Dois métodos QuEChERS modifica$\operatorname{dos}^{[126,127]}$, um empregando tampão acetato e o outro tampão citrato, foram adotados, respectivamente, pela AOAC Official Method (2007) 
e pela European Committee for Standardization (CEN) Standard Method EN 15662 (2008). A escolha do método QuEChERS depende do tipo de amostra e das características dos agrotóxicos, e visa obter recuperações elevadas e solucionar o problema da instabilidade dos compostos em determinados $\mathrm{pH}^{[128]}$.

Ao contrário do clean-up em SPE que utiliza cartucho, coluna ou disco ${ }^{[129]}$, no método QuEChERS a extração em fase sólida dispersiva (Dispersive Solid-Phase Extraction, d-SPE) permite que o clean-up de interferentes e a redução de água residual sejam efetuados de forma rápida e simultânea. Esta etapa de remoção de água proporciona um extrato final de menor polaridade, o que facilita a precipitação de coextrativos ou interferentes polares e permite a injeção direta do extrato final nos equipamentos de CG ou $\mathrm{CL}^{[95,130]}$. Dependendo da composição da amostra, pode-se optar por sorventes com características diferentes ou misturas desses, como amina primária secundária (Primary Secondary Amine - PSA) ou propiletilenodiamina, carbono grafinitizado (Grafitized Carbon Black - GCB), octadecilsiloxano (C18), entre outros. Para amostras de morango, o sorvente mais recomendando é o PSA, que possui uma estrutura bidentada com efeito quelante elevado, que promove a remoção de açúcares, ácidos graxos, ácidos orgânicos e pigmentos como antocianinas.

Atualmente, o método QuEChERS está sendo muito utilizado nas determinações de multirresíduos de agrotóxicos em amostras de alimentos, devido a uma série de vantagens, entre elas: porcentagens altas de recuperação dos agrotóxicos com diferentes propriedades físico-químicas; não utilização de solventes clorados, contribuindo para a química verde; baixo custo e manipulação fácil. Porém, o fator de concentração que pode ser alcançado é menor quando comparado ao que pode ser obtido empregando a SPE. Em vista disso, esse é um parâme- tro importante que deve ser considerado, pois, dependendo do tipo de detector a ser utilizado, os LMR estabelecidos podem não ser atingidos.

\subsection{Determinação de resíduos de agrotóxicos e componentes em morango com destaque para cromatografia líquida moderna}

Inicialmente os resíduos de agrotóxicos eram analisados por métodos colorimétricos e cromatográficos não muito sofisticados, sendo que determinavam poucos analitos em alguns tipos de amostras ${ }^{[37]}$. Atualmente, o monitoramento de resíduos de agrotóxicos é realizado para várias classes simultaneamente, por meio de uma extração associada a uma técnica analítica instrumental, sendo a CL e CG as técnicas mais utilizadas $^{[131-134]}$.

A CLAE passou a ter seu uso intensificado em várias áreas e na década de 70, Snyder propôs uma denominação mais abrangente para a técnica, Modern Liquid Chromatography. Este nome descreve a técnica instrumental desenvolvida em contraposição à CL clássica, não tendo sentido temporal, ou seja, moderna por ser contemporânea ${ }^{[135,136]}$. Atualmente, devido à grande expansão da CL moderna, em contraste ao uso reduzido da CL clássica, muitas vezes, emprega-se somente a denominação de cromatografia líquida (CL).

As principais vantagens da CL incluem a capacidade de realizar separações e determinações qualitativas e quantitativas de uma grande variedade de compostos presentes em diversos tipos de amostras, independente da volatilidade, estabilidade térmica e polaridade, em escala de tempo de poucos minutos, com alta resolução, eficiência e repetibilidade ${ }^{[137,138]}$.

A cromatografia gasosa é uma técnica com um poder de resolução excelente, o que facilita a análise de diversos analitos numa mesma amostra $^{[139]}$. Entretanto, a polaridade e instabilidade 
térmica de alguns agrotóxicos, tornam as análises por CG mais difíceis ${ }^{[140]}$, fazendo-se necessária uma etapa de derivatização, o que pode aumentar o tempo e o custo da análise.

As determinações por CL podem ser realizadas empregando-se vários tipos de detectores, sendo os mais utilizados o arranjo de diodos (DAD) e o espectrômetro de massas (EM), que realizam análises qualitativas e/ou quantitativas.

No cenário atual, a CL acoplada à espectrometria de massas tem-se mostrado uma das técnicas mais poderosas para a determinação de resíduos de agrotóxicos ${ }^{[141]}$. O destaque da CL se deve à tendência ao emprego de agrotóxicos mais polares, por serem menos persistentes e tóxicos que os apolares. $\mathrm{O}$ acoplamento das duas técnicas combina as vantagens de ambas, a alta seletividade e a eficiência de separação da CL e a informação estrutural, a massa molar e a melhora na seletividade e detectabilidade da espectrometria de massas ${ }^{[136,142-145]}$.

A espectrometria de massas sequencial (em série ou Tandem) está sendo cada vez mais utilizada na área química, principalmente em análises de resíduos de agrotóxicos em alimentos. Esse modo tem sido considerado uma ferramenta de identificação e confirmação, no qual o monitoramento dos fragmentos fornece maior discriminação que um único estágio, reduzindo a necessidade de etapas excessivas de preparo de amostra; diminui resultados falsos positivos, especialmente em amostras complexas, como frutas e vegetais; permite a identificação de analitos a níveis de ultratraços (ng ou menor) e com características físico-químicas diferentes; resulta em menor tempo e custo das análises, com maior detectabilidade e seletividade ${ }^{[102,146-148]}$. $\mathrm{O}$ aumento da seletividade do detector reduz a influência do efeito matriz e aumenta a detectabilidade, uma vez que aumenta a razão sinal/ruído
(Signal to Noise - S/N), e consequentemente, permite que os LMR sejam atingidos com maior facilidade ${ }^{[132,142]}$.

O desenvolvimento de novos métodos ou modificações dos já existentes requer uma etapa de validação. Um guia de validação muito importante para análise de resíduos de agrotóxicos em alimentos é o Sanco (Method Validation and Quality Control Procedures for Pesticide Residues Analysis in Food And Feed ${ }^{[149]}$ que é direcionado às aplicações que envolvem determinações por CL e CG acopladas a EM.

Alguns trabalhos que ilustram o desenvolvimento e a validação de métodos de determinação de resíduos de agrotóxicos e de componentes do morango, empregando as técnicas citadas, serão apresentados.

Soler et al. ${ }^{[103]}$ compararam duas técnicas de extração: MSPD, utilizando C18 como dispersante, diclorometano e metanol como eluente, e SLE com solvente acetato de etila, na determinação de nove agrotóxicos (acrinatrina, carbosulfano, ciproconazol, $\gamma$-cialotrina, cresoxim metilíco, pirifenox, piriproxifem, propanil, e tebufempirado) em amostras de laranja e morango, empregando CL-EM/EM. Recuperações na faixa de (51,5-108)\% e de (59-101)\% e estimativas de desvio padrão relativo de $<16 \%$ e $<17 \%$, foram obtidas para MSPD e SLE, respectivamente. Contudo, para a maioria dos agrotóxicos, os limites de quantificação (LQ) foram melhores para SLE $(0,01-0,4) \mathrm{mg} \mathrm{kg}^{-1}$ que para MSPD (0,05-2) $\mathrm{mg} \mathrm{kg}^{-1}$. Os autores concluíram que a SLE permitiu melhor detectabilidade que a MSPD, devido aos valores dos LQ, porém a MSPD tem a vantagem de utilizar menor volume de solvente.

Um trabalho que é considerado ambientalmente correto, por utilizar água como solvente de extração, foi desenvolvido por Falqui-Cao et al. ${ }^{[104]}$. Os autores empregaram 
duas técnicas de extração, assistidas por micro-ondas focalizada (Focused Microwave-Assisted Extraction - FMAE) e SPME acoplada com CLAE-DAD para determinação de cinco agrotóxicos (azoxistrobina, bupirimato, carbendazim, dietofencarb, napropamida) em amostras de morangos. As amostras foram extraídas com água por FMAE e o extrato aquoso foi exposto a uma fibra de poli(dimetilsiloxano)/divinilbenzeno (PDMS/DVB) na SPME. Os agrotóxicos foram dessorvidos na interface SPME/CLAE para sua quantificação, com limites de detecção inferiores a $\mu \mathrm{g} \mathrm{kg}^{-1}(\mathrm{ppb})$, que estão abaixo dos LMR.

Em um trabalho desenvolvido por Soler et al. ${ }^{[119]}$, empregaram-se três tipos de analisadores de massas: Triplo Quadrupolo (QqQ), Quadrupolo Armadilha de Íons (Ion Trap - QIT) e Quadrupolo por Tempo por Voo (QuadrupoleTime-of-Flight - QqTOF) na determinação de doze de agrotóxicos (acrinatrina, bupirimato, buprofezina, ciproconazol, $\gamma$-cialotrina, fluvalinato, hexaflumurom, cresoxim metilíco, propanil, pirifenox, piriproxifem e tebufenpirado), em seis matrizes (cereja, damasco, laranja, morango, pera e pêssego) e extração por PLE. As estimativas do desvio padrão relativo foram menores para QqQ (5-12)\%, em comparação ao QIT (6-15)\% e QqTOF (14-19)\%. A faixa linear dinâmica foi pelo menos de três ordens de grandeza maior para o QqQ, enquanto para QIT e QqTOF foram de duas e uma ordem, respectivamente. O QqQ foi pelo menos 20 vezes mais sensível que QIT e QqTOF. Contudo, o QqQ não foi adequado para identificação do etirimol que é o metabólito do bupirimato. Portanto, verifica-se que o analisador ideal depende do tipo específico de análise, que pode ser qualitativa ou quantitativa.

A hifenação de diferentes técnicas de extração pode ser uma alternativa interessante para análises de resíduos de agrotóxicos. Um método desenvolvido por Urruty e Montory ${ }^{[150]}$ utilizou MAE e SPME acopladas à CG-EM ou CLAE-DAD para análise de vinte agrotóxicos em morangos. Os resultados mostraram que o método desenvolvido foi simples, rápido, ambientalmente correto e de baixo custo.

Sagratini et al. ${ }^{[151]}$ analisaram agrotóxicos das classes carbamato e fenilureia em sucos de frutas (cereja, laranja, maçã e morango), empregando SPME acoplada à CL/EM e CL/QIT- EM. Os agrotóxicos foram extraídos com três fibras diferentes, Carbowax/resina template (CW/TPR) de $50 \mu \mathrm{m}$, poli(dimetilsiloxano)/divinilbenzeno (PDMS/DVB) de $60 \mu \mathrm{m}$ e poliacrilato de $85 \mu \mathrm{m}$, sendo que as duas primeiras fibras forneceram melhores recuperações. Os autores verificaram que tanto o monitoramento SIM (Selected Ion Monitoring) como o MRM (Multiple Reaction Monitoring) forneceram resultados adequados, porém o MRM mostrou maior detectabilidade.

Existe uma diversidade de métodos analíticos para determinação de resíduos de agrotóxicos em morangos por CL, com diferentes justificativas para o seu uso, porém deve-se priorizar um método abrangente, rápido, confiável, de custo baixo, ambientalmente correto e que seja capaz de analisar diversas classes de agrotóxicos com alta detectabilidade.

A CL é muito útil para determinações de agrotóxicos e também de componentes no morango, responsáveis pelos atributos sensoriais como sabor, aparência e textura. Esses componentes podem diferir em quantidades, pois dependem do tipo de cultivar, e das condições climáticas nas quais o morango foi cultivado ${ }^{[20]}$. Outro fator importante, como taxa de amadurecimento, também influencia nas características do morango.

Montero et al. ${ }^{[152]}$ estudaram a taxa de açúcares, ácidos, compostos fenólicos, substâncias pécticas na cultivar Chandler e determinaram 
o período ótimo de frutificação, de 28-35 dias, sendo que o $28^{\circ}$ dia corresponde ao melhor estágio de desenvolvimento (peso maior) e amadurecimento (maior razão açúcar:ácido) com coloração e textura apropriadas para o consumo. Esse estudo foi realizado empregando CLAE-DAD e CLAE com detector por Índice de Refração (IR).

Entre os diferentes compostos presentes no morango, os ácidos orgânicos, vitamina C, carboidratos e antocianinas são os mais frequentemente analisados, devido as suas contribuições para as propriedades sensoriais e nutricionais. Mangas et al. ${ }^{[153]}$ determinaram açúcares (frutose, glucose e sucrose), ácidos orgânicos (málico, químico, cítrico e fumárico) e vitamina $\mathrm{C}$ em morangos, sendo que, entre os açúcares, a frutose foi encontrada em maior abundância e, entre os ácidos, o cítrico e málico foram encontrados em maior quantidade. Os compostos foram analisados por CLAE em fase reversa (FR) com detector UV-Vis ou por troca cationica com detector por IR.

Herrera e Castro ${ }^{[154]}$ desenvolveram um método semiautomático para determinação de compostos fenólicos (catequina, naringina, rutina, naringenina, ácido elágico, quercetina e kaempferol) em amostras de morango, usando a extração assistida por ultrassom e determinação por CLAE-DAD. Silva et al. ${ }^{[155]}$ também realizaram um estudo sobre a determinação de 25 pigmentos de antocianinas, que são compostos fenólicos, em cinco cultivares de morango, por CLAE com detecção dupla on-line, DAD e EM. A concentração de antocianinas variou de 200-600 mg kg-1, sendo a forma predominante a pelargonidina 3-glucosídeo, seguida de pelargonidina 3-rutinosídeo e cianidina 3-glucosídeo, numa soma total de mais de $95 \%$ de antocianinas em morango. Foi encontrada uma variabilidade marcante entre as concentrações de antocianina em amostras de uma mesma espécie e colheita, indicando uma forte influência do grau de maturidade, fatores climáticos e edáficos e armazenamento pós-colheita.

É importante notar que, os componentes do morango são dependentes das condições ambientais como também do tipo de cultivar estudado. Portanto, deve-se sempre descrever detalhamente as condições que foram utilizadas na produção agrícola do morango para efeitos comparativos, garantindo maior confiabilidade dos resultados.

\section{Considerações finais}

O crescimento da população mundial demanda maior produção de alimentos, o que tem provocado aumento na utilização de agrotóxicos na produção agrícola. Como consequência, resíduos tóxicos destes compostos podem contaminar o meio ambiente, as frutas e os vegetais que são consumidos por crianças, adultos e idosos.

Existem várias fontes que induzem o monitoramento de resíduos de agrotóxicos como o comércio exterior, ou seja, a exportação de alimentos, pois uma concentração acima dos limites internacionalmente aceitos pode causar a devolução dos alimentos ou abalar a relação exportação/importação entre diferentes países. Outra contribuição de grande importância é a preocupação e a conscientização cada vez maior dos órgãos de pesquisa e dos consumidores acerca dos malefícios decorrentes do contato e da ingestão dessas substâncias tóxicas, requerendo maiores informações sobre o produto a ser consumido.

Infelizmente, não há variedades de morango totalmente resistentes a pragas e doenças, e o controle químico, embora seja uma solução, com o decorrer do tempo, os micro-organismos podem 
adquirir resistência aos agrotóxicos, requerendo a aplicação de uma dose maior. Por isso, os produtores de morango devem fazer uso dos procedimentos das BPA, empregando agrotóxicos seletivos, observarem o período de carência, a dosagem correta, a segurança dos trabalhadores rurais, recorrerem a métodos alternativos de controle como uma opção auxiliar, utilizarem mudas de morangos certificadas, cultivarem o morango em ambientes protegidos e em condições controladas, sempre que possível optarem pela produção orgânica, com maior área de cultivo, e diminuírem o custo da produção, para atenderem uma parcela maior de consumidores e contribuírem com menor liberação de resíduos. A alternativa para diminuir os riscos dos agrotóxicos é uma maior fiscalização sobre as vendas, usos de agrotóxicos e o destino das embalagens vazias que devem ser lavadas e armazenadas em locais apropriados.

Finalmente, deve-se tentar unir uma produção agrícola mais adequada com o monitoramento rigoroso de resíduos de agrotóxicos nos alimentos, para minimizar os impactos ambientais e a contaminação dos alimentos; garantir a segurança dos trabalhadores rurais e fornecer alimentos mais saudáveis para os consumidores.

O monitoramento de resíduos de agrotóxicos em alimentos deve basear-se em uma técnica de preparo de amostra rápida, econômica, ambientalmente correta e segura como o método QuEChERS, e em uma técnica de separação rápida e eficiente como a CL acoplada a um detector de alta detectabilidade e seletividade como o espectrômetro de massas, que hoje se constitui em uma das ferramentas mais poderosas de detecção analítica.

\section{Agradecimentos}

Os autores agradecem à FAPESP, ao CNPq e à CAPES o apoio financeiro e à Dra. Liane Maldaner sua valiosa colaboração na revisão final.

\section{Referências}

1 Oliveira RP, Scivittaro WB. Desempenho produtivo de mudas nacionais e importadas de morangueiro. Revista Brasileira de Fruticultura 2006; 28(3):520. http://dx.doi.org/10.1590/S0100-29452006000300040

2 Françoso ILT, Couto MAL, Canniatti-Brazaca SG, Arthur V. Alterações físico-químicas em morangos (Fragaria anassa Duch.) irradiados e armazenados. Ciência e Tecnologia de Alimentos 2008; 28(3):614. http://dx.doi.org/10.1590/S0101-20612008000300017

3 Camargo Filho WP, Camargo FP. Análise da produção de morango dos Estados de São Paulo e Minas Gerais e do mercado da CEAGESP. Informações Econômicas 2009; 39(5):42-50.

4 Figueiredo FC, Botrel PP, Teixeira CP, Petrazzini LL, Locarno M, Carvalho JG. Pulverização foliar e fertirrigação com silício nos atributos físico-químicos de qualidade e índices de coloração do morango. Ciência e Agrotecnologia 2010; 34(5):1306. http:// dx.doi.org/10.1590/S1413-70542010000500032

5 Giménez G, Andriolo J, Godoi R. Cultivo sem solo do morangueiro. Ciência Rural 2008; 38(1):273-279. http://dx.doi.org/10.1590/S0103-84782008000100048

6 Embrapa. Centro Nacional de Pesquisa de Hortaliças. Tabela de composição nutricional das hortaliças [cited 2011 nov.]. Available from: http://www.cnph.embrapa. br/util/tabelahortalicas.htm.

7 Embrapa. Embrapa Clima Temperado. Sistema de produção do morango [cited 2011 nov.]. Available from: http://sistemasdeproducao.cnptia.embrapa.br.

8 Bordignon Junior CL, Francescatto V, Nienow AA, Calvete E, Reginatto FH. Influence of the extraction solution $\mathrm{pH}$ on the content of anthocyanins in strawberry fruits. Ciência e Tecnologia de Alimentos 2009; 29(1):183-188. http://dx.doi.org/10.1590/ S0101-20612009000100028

9 Hakkinen SH, Torronen AR. Content of flavonols and selected phenolic acids in strawberries and Vaccinium species: influence of cultivar, cultivation site and technique. Food Research International 2000; 33:517-524. http://dx.doi.org/10.1016/S09639969(00)00086-7 
10 Seeram NP, Lee R, Scheuller S, Heber D. Identification of phenolic compounds in strawberries by liquid chromatography electrospray ionization mass spectroscopy. Food Chemistry 2006; 97(1):1-11. http:// dx.doi.org/10.1016/j.foodchem.2005.02.047

11 Rocha DA, Abreu CMP, Corrêa AD, Santos CD, Fonseca EWN. Análise comparativa de nutrientes funcionais em morangos de diferentes cultivares da região de Lavras-MG. Revista Brasileira de Fruticultura 2008; 30(4):1124-1128. http://dx.doi.org/10.1590/ S0100-29452008000400046

12 Henrique CM, Cereda MP. Utilização de biofilmes na conservação pós-colheita de morango (Fragaria Ananassa Duch) cv IAC Campinas. Ciência $e$ Tecnologia de Alimentos 1999; 19(2):1. http://dx.doi. org/10.1590/S0101-20611999000200014

13 Ponce AR, Bastiani MID, Minim VP, Vanetti MCD. Características físico-químicas e microbiológicas de morango minimamente processado. Ciência $e$ Tecnologia de Alimentos. No prelo.

14 Moraes IVM, Cenci AS, Benedetti BC, Mamede AMGN, Soares AG, Barboza HTG. Características físicas e químicas de morango processado minimamente e conservado sob refrigeração e atmosfera controlada. Ciência e Tecnologia de Alimentos 2008: 28(2):274. http://dx.doi.org/10.1590/ S0101-20612008000200003

15 Siqueira HH, Boas BMV, Silva JD, Nunes EE, Lima LCO, Santana MTA. Armazenamento de morango sob atmosfera modificada e refrigeração. Ciência $e$ Agrotecnologia 2009; 33:1712-1715.

16 Cenci SA, Gomes CAO, Alvarenga ALB, Freire Juinior M. Boas práticas de processamento mínimo de vegetais na agricultura familiar. In: Nascimento Neto F, organizador. Recomendações básicas para a aplicação das boas práticas agropecuárias e de fabricação na agricultura familiar [cited 2011 oct.]. Brasília: Embrapa Informação Tecnológica; 2006. p.@\#@59-63. Available from: http://www.ceasa.gov. br/dados/publicacao/pub10.pdf.

17 Reis KC, Siqueira HH, Alves AP, Silva JD, Lima LCO. Efeito de diferentes sanificantes sobre a qualidade de morango cv. Oso Grande. Ciência e Agrotecnologia 2008; 32(1):196-202. http://dx.doi.org/10.1590/ S1413-70542008000100029

18 Andriguet JR, Kososk AR. Desenvolvimento $e$ conquistas da produção integrada de frutas no Brasil [cited 2011 sept.]. Brasília: Secretaria de Comércio
Exterior; 2005. Available from: http://www.cnpuv. embrapa.br/tecnologias/pin/pdf/p_01.pdf.

19 Ciscato CHP, Gebara AB, Monteiro SH. Pesticide residue monitoring of Brazilian fruit for export 20062007. Food Additives and Contaminants: Part B 2009; 2(2):140-145.

20 Resende JTV, Camargo LKP, Argandoña EJS, Marchese A, Camargo CK. Análise sensorial e caracterização química de frutos de morango. Horticultura Brasileira 2008; 26(3):371. http://dx.doi.org/10.1590/S010205362008000300015

21 Otto RF, Morakami RK, Reghin MY, Caíres EF. Cultivares de morango de dia neutro: produção em função de doses de nitrogênio durante o verão. Horticultura Brasileira 2009; 27(2):217. http://dx.doi. org/10.1590/S0102-05362009000200017

22 Oliveira RP, Scivittaro WB. Produção de frutos de morango em função de diferentes períodos de vernalização das mudas. Horticultura Brasileira 2009; 27(1):91-95. http://dx.doi.org/10.1590/S010205362009000100018

23 Oliveira RP, Scivittaro WB. Produção de morangueiro cv. "Cegnidarem" sob túnel plástico. Ciência Rural 2008; 38(9):2613-2617. http://dx.doi.org/10.1590/ S0103-84782008005000033

24 Madail JCM, Antunes LEC, Reisser Junior C, Belarmino LC, Neutzling DM, Silva BA. Economia da produção de morango: estudo de caso de transição para produção integrada. Boletim de Pesquisa $e$ Desenvolvimento 2007; 53:1-25.

25 Henz GP. Desafios enfrentados por agricultores familiares na produção de morango no Distrito Federal. Horticultura Brasileira 2010; 28(3):260-265. http://dx.doi.org/10.1590/S0102-05362010000300003

26 Tessarioli Neto J, Ortigoza LER, Verdial MF. Produção de mudas de cultivares de morangueiro em duas épocas de coleta. Horticultura Brasileira. 2003; 21(2):231-233. http://dx.doi.org/10.1590/S0102-05362003000200022

27 Resende JTV, Morales RGF, Faria MV, Rissinin ALL, Camargo LKP, Camargo CK. Produtividade e teor de sólidos solúveis de frutos de cultivares de morangueiro em ambiente protegido. Horticultura Brasileira 2010; 28(2):185. http://dx.doi.org/10.1590/ S0102-05362010000200008

28 Villela Júnior LVE, Araújo JAC, Factor TL. Análise do resfriamento da solução nutritiva para cultivo hidropônico do morangueiro. Engenharia Agrícola 
2004; 24(2):338. http://dx.doi.org/10.1590/S010069162004000200012

29 Verdial MF, Minami JTNK, Scarpare Filho JA, Christoffoleti PJ, Scarpare FV, Barela JF et al. Vernalização em cinco cultivares de morangueiro. Ciência Rural 2007; 37(4):976. http://dx.doi. org/10.1590/S0103-84782007000400009

30 Fadini MAM, Pallini A, Venzon M. Controle de ácaros em sistema de produção integrada de morango. Ciência Rural 2004; 34(4):1271. http://dx.doi. org/10.1590/S0103-84782004000400053

31 Durner EF, Poling EB, Maas JL. Recent advances in strawberry plug transplant technology. Hort Technology 2002; 12(4):545-550.

32 Andriolo JL, Jänisch DI, Schmitt OJ, Dal Picio M, Cardoso FL, Erpen L. Doses de potássio e cálcio no crescimento da planta, na produção e na qualidade de frutas do morangueiro em cultivo sem solo. Ciência Rural 2010; 40(2):267. http://dx.doi.org/10.1590/ S0103-84782010000200003

33 Agência Nacional de Vigilância Sanitária - ANVISA. Programa de Análise de Resíduos de Agrotóxicos em Alimentos - PARA. Minuta de nota técnica para divulgação de relatório de atividades de 2010. Brasília: ANVISA; 2011.

34 Agência Nacional de Vigilância Sanitária - Anvisa. Resíduos de agrotóxicos em alimentos. Revista Saúde Pública 2006; 40(2):361. http://dx.doi.org/10.1590/ S0034-89102006000200028

35 Brasil. Ministério da Agricultura, Pecuária e Abastecimento. Portaria no 329, de 02 de setembro de 1985. Proibe em todo o território nacional, a comercialização, o uso e a distribuição dos produtos agrotóxicos organoclorados que especifica [cited 2011 sept.]. Diário Oficial da República Federativa do Brasil, Brasília, DF, 1985 set. Available from: http://www. anvisa.gov.br/legis/portarias/329_85.htm.

36 D'Amato C, Torres JPM, Malm O. DDT (Dicloro Difenil Tricloroetano): Toxicidade E Contaminação Ambiental - uma revisão. Química Nova 2002; 25(6):995. http://dx.doi.org/10.1590/S010040422002000600017

37 Stoppelli IMBS, Magalhães CP. Saúde e segurança alimentar: a questão dos agrotóxicos. Ciência \& Saúde Coletiva 2005; 10(91):91-100. http://dx.doi. org/10.1590/S1413-81232005000500012

38 Jardim ICSF, Andrade JA, Queiroz SCN. Resíduos de agrotóxicos em alimentos: uma preocupação ambiental global - um enfoque às maçãs. Química. Nova 2009; 32(4):996. http://dx.doi.org/10.1590/ S0100-40422009000400031

39 Brasil. Presidência da República. Casa Civil. Subchefia para Assuntos Jurídicos. Lei Federal no 7.802, de 11 de julho de 1989. Dispõe sobre a pesquisa, experimentação, produção, embalagem e rotulagem, o transporte, o armazenamento, a comercialização, a propaganda comercial, a utilização, a importação, a exportação, o destino final dos resíduos e embalagens, o registro, a classificação, o controle, a inspeção e a fiscalização de agrotóxicos, seus componentes e afins, e dá outras providências [cited 2011 sept.]. Diário Oficial da República Federativa do Brasil, Brasília, DF, 1989 jul. 12. Available from: http://www.planalto.gov. br/CCIVIL_03/LEIS/L7802.htm.

40 Brasil. Presidência da República, Casa Civil. Subchefia para Assuntos Jurídicos. Decreto no 4.074, de 04 de janeiro de 2002. Regulamenta a Lei $n^{\circ} 7.802$, de 11 de julho de 1989, que dispõe sobre a pesquisa, a experimentação, a produção, a embalagem e rotulagem, o transporte, o armazenamento, a comercialização, a propaganda comercial, a utilização, a importação, a exportação, o destino final dos resíduos e embalagens, o registro, a classificação, o controle, a inspeção e a fiscalização de agrotóxicos, seus componentes e afins, e dá outras providências [cited 2011 sept.]. Diário Oficial da República Federativa do Brasil, Brasília, DF, 2002 jan. Available from: http://www.planalto.gov.br/ CCIVIL_03/decreto/2002/D4074.htm.

41 United States Environmental Protection Agency - EPA. About pesticides [cited 2011 sept.]. Available from: http://www.epa.gov/pesticides/about/index.htm.

42 Sanches SM, Silva CHTP, Campos SX, Vieira EM. Pesticidas e seus respectivos riscos associados à contaminação da água. Pesticidas: Revista de Ecotoxicologia e Meio Ambiente 2003; 13:53-58.

43 Ribeiro ML, Lourencetti C, Polese L, Navickiene S, Oliveira LC. Pesticidas: Usos e riscos para o meio ambiente. Holos Environment 2008; 8(1):53-71.

44 Planeta Orgânico. Agrotóxicos [cited 2011 oct.]. Available from: http://www.planetaorganico.com.br/ agrothist1.htm.

45 São Paulo (Estado). Secretaria da Saúde do Estado de São Paulo. Superintendência de Controle de Endemias - SUCEN. Toxicologia de Praguicidas [cited 2011 sept.]. Available from: http://www.sucen.sp.gov.br/ downl/segtrb/sequi5.pdf. 
46 Faria NMX, Fassa AG, Facchini LA. Intoxicação por agrotóxicos no Brasil: os sistemas oficiais de informação e desafios para realização de estudos epidemiológicos. Ciência \& Saúde Coletiva 2007; 12(1):25-38. http:// dx.doi.org/10.1590/S1413-81232007000100008

47 Velasco LOM, Capanema LXL. O setor de agroquímicos. BNDES Setorial 2006; 24:69-96.

48 Associação Brasileira dos Defensivos Genéricos AENDA. Genéricos [cited 2011 sept.]. Available from: http://aenda.org.br.

49 Sindicato Nacional da Indústria de Produtos para Defesa Agrícola - SINDAG. Dados de Mercado [cited 2011 sept.]. 2011. Available from: http://www.sindag. com.br.

50 Sabik H, Jeannot R, Rondeau B. Multiresidue methods using solid-phase extraction techniques for monitoring priority pesticides, including triazines and degradation products, in ground and surface waters. Journal of Chromatography A 2000; 885: 217-236. http://dx.doi.org/10.1016/S0021-9673(99)01084-5

51 Associação Brasileira das Indústrias de Química Fina, Biotecnologia e suas Especialidades - Abifina. Saldo Comercial [cited 2011 sept.]. Available from: http:// www.abifina.org.br/saldocom.asp.

52 Instituto Salus. Uso de agrotóxicos no Brasil lidera ranking mundial [cited 2011 nov.]. Available from: http://www.institutosalus.com/noticias/ saude-publica/uso-de-agrotoxicos-no-brasil-lideraranking-mundial.

53 Agrosoft Brasil. Brasil, maior consumidor de agrotóxicos do mundo [cited 2011 sept.]. Jornal Agrosoft, 2011. Available from: http://www.agrosoft. org.br/agropag/218371.htm.

54 Caldas ED, Souza LCKR. Avaliação de risco crônico da ingestão de resíduos de pesticidas na dieta brasileira. Revista de Saúde Pública 2000; 34(5):529-537. http:// dx.doi.org/10.1590/S0034-89102000000500014

55 Codex Alimentarius Commission. Codex pesticides residues in food online database [cited 2011 oct.]. Available from: http://www.codexalimentarius.net/ pestres/data/index.html.

56 Agência Nacional de Vigilância Sanitária - ANVISA. Consulta Pública no 43, de 2 de junho de 2005. [cited 2011 sept.]. Diário Oficial da República Federativa do Brasil, Brasília, DF, 2005 jun. 6. Available from: http:// www4.anvisa.gov.br/base/visadoc/CP/CP\%5B105591-0\%5D.PDF.
57 Agência Nacional de Vigilância Sanitária - ANVISA. Programa de Análise de Resíduos de Agrotóxicos em Alimentos - PARA. Minuta de nota técnica para divulgação dos resultados do PARA de 2008. Brasília: ANVISA; 2009.

58 Agência Nacional de Vigilância Sanitária - ANVISA. Programa de Análise de Resíduos de Agrotóxicos em Alimentos - PARA. Minuta de nota técnica para divulgação de relatório de atividades de 2009. Brasília: ANVISA; 2010.

59 Fermam RKS, Antunes AMS. Uso de defensivos agrícolas, limites máximos de resíduos e impacto no comércio internacional: Estudo de caso. Revista de Economia e Agronegócio 2009; 7(2):197-214.

60 Ferla NJ, Marchetti MM, Gonçalves D. Ácaros predadores (Acari) associados à cultura do morango (Fragaria sp., Rosaceae) e plantas próximas no Estado do Rio Grande do Sul. Biota Neotropica 2007; 7(2):1. http://dx.doi.org/10.1590/S1676-06032007000200012

61 Domingues RJ, Töfoli JG, Oliveira SHF, Garcia Júnior O. Controle químico da Flor Preta (Colletotrichum Acutatum Simmonds) do morangueiro em condições de campo. Arquivos do Instituto Biológico 2001; 68(2):37-42.

62 Ueno B. Antracnose do morangueiro ("Flor Preta") causada por Colletotrichum acutatum. Instituto Agronômico do Paraná 1996; ano IX, 119:1-11.

63 Kososki RM, Furlanetto C, Tomita CK, Café Filho AC. Efeito de fungicidas em Colletotrichum Acutatum e controle da Antracnose do Morangueiro. Fitopatologia Brasileira 2001; 26(3):662. http://dx.doi.org/10.1590/ S0100-41582001000300016

64 Clevo W, Clem T. Why farmers continue to use pesticides despite environmental, health and sustainability costs. Ecological Economics 2001; 39: 449-462. http://dx.doi.org/10.1016/S09218009(01)00238-5

65 Lintelmann J, Katayama A, Kurihara N, Shore L, Wenzel A. Endocrine disruptors in the environment (IUPAC Technical Report). Pure and Applied Chemistry 2003; 75(5):631-681. http://dx.doi. org/10.1351/pac200375050631

66 McKinlay R, Plant JA, Bell JNB, Voulvoulis, N. Endocrine disrupting pesticides: Implications for risk assessment. Environment International 2008; 34:168183. PMid:17881056. http://dx.doi.org/10.1016/j. envint.2007.07.013 
67 Schwarzenbach RP, Gschwend PM, Imboden DM. Environmental Organic Chemistry.2rd@\#@ed. WileyInterscience; 1995.

68 Rebelo FM, Caldas ED, Heliodoro VO, Rebelo RM. Intoxicação por agrotóxicos no Distrito Federal, Brasil, de 2004 a 2007 - análise da notificação ao Centro de Informação e Assistência Toxicológica. Ciência \& Saúde Coletiva 2011, 16(8):3493-3502. http://dx.doi. org/10.1590/S1413-81232011000900017

69 Bochner R. Sistema Nacional de Informações TóxicoFarmacológicas SINITOX e as intoxicações humanas por agrotóxicos no Brasil. Ciência \& Saúde Coletiva 2007; 12(1):73-89. http://dx.doi.org/10.1590/S141381232007000100012

70 Ward MH, Nuckols JR, Weigel SJ, Maxwell SK, Cantor KP, Miller RS. Identifying populations potentially exposed to agricultural pesticides using remote sensing and a geographic information system. Environmental Health Perspectives 2000; 108(1):512. PMid:10622770. PMCid:1637858. http://dx.doi. org/10.2307/3454289

71 Araújo ACP, Nogueira DP, Augusto LGS. Impacto dos praguicidas na saúde: estudo da cultura de tomate Revista de Saúde Pública 2000; 34(3):309-313. http:// dx.doi.org/10.1590/S0034-89102000000300016

72 Brasil. Ministério da Saúde. Secretaria de atenção à saúde. Departamento de ações programáticas estratégicas. Área técnica de saúde do trabalhador. Diretrizes para atenção integral à saúde do trabalhador de complexidade diferenciada. Protocolo de atenção à saúde dos trabalhadores expostos a agrotóxicos [cited 2011 aug.]. Brasília; 2006. Available from: http:// portal.saude.gov.br/portal/arquivos/pdf/integra_ agrotoxicos.pdf.

73 Silva JJO, Alves SR, Meyer A, Perez F, Sarcinelli $\mathrm{PN}$, Mattos RCOC et al. Influência de fatores socioeconômicos na contaminação por agrotóxicos, Brasil. Revista de Saúde Pública 2001; 35(2):130-135. PMid:11359198. http://dx.doi.org/10.1590/S003489102001000200005

74 Kato M, Garcia EG, Wünsch Filho V. Antracnose do morangueiro ("Flor Preta") causada por Colletotrichum acutatum. Revista Brasileira de Saúde Ocupacional 2007; 32(116):06-10.

75 Farias R. M, Martins CR. Produção Integrada de Frutas - Revisão Bibliográfica. Revista da FZVA 2002; 9(1):33-47.
76 Andrigueto JR, Nasser LCB, Teixeira JMA, Simon G, Veras MCV, Medeiros SAF et al. Produção Integrada de Frutas - PIF e Sistema Agropecuário de Produção Integrada - SAPI no Brasil. Ministério da Agricultura; 2008.

77 Dores EFGC, De-Lamonica-Freire EM. Contaminação do ambiente aquático por pesticidas: vias de contaminação e dinâmica dos pesticidas no ambiente aquático. Pesticidas: Revista de Ecotoxicologia e Meio Ambiente 1999; 9(1):18.

78 Martínez RC, Gonzalo ER, Laespada MEF, Román FJSS. Evaluation of surface- and ground-water pollution due to herbicides in agricultural areas of Zamora and Salamanca (Spain). Journal of Chromatography A 2000, 869:471-480. http://dx.doi. org/10.1016/S0021-9673(99)01188-7

79 Ribeiro ML, Lourencetti C, Pereira SY, Marchi MRR. Contaminação de águas subterrâneas por pesticidas: avaliação preliminar. Química Nova 2007, 30(3):688-694. http://dx.doi.org/10.1590/S010040422007000300031

80 Dores EFGC, De-Lamonica-Freire EM. Aquatic environment contamination by pesticides. Case study: water used for human consumption in Primavera do Leste, Mato Grosso - preliminary analyses. Química Nova 2001; 24(1):27-36. http://dx.doi.org/10.1590/ S0100-40422001000100007

81 Castillo LE, De La Cruz E, Ruepert C. Ecotoxicology and pesticides in tropical aquatic ecosystems of Central America. Environmental Toxicology \& Chemistry 1997; 16:41-51. http://dx.doi.org/10.1002/ etc. 5620160104

82 Eichelberger JW, Lichtenberg JJ. Persistence of pesticides in river water. Environmental Science \& Technology 1971; 5:541-544. http://dx.doi. org/10.1021/es60053a002

83 Toassa EC, Machado EHS, Szarfarc SC, Philippi ST, Leal GVS. Alimentos orgânicos e o meio ambiente. Journal of the Brazilian Society of Food and Nutrition 2009; 34(1):175-184.

84 Associação de Agricultura Orgânica - AAO. Agricultura orgânica [cited 2011 nov.]. Available from: http://aao.org.br/aao/.

85 Brasil. Presidência da República. Casa Civil. Subchefia para Assuntos Jurídicos. Decreto no 6.323, de 27 de dezembro de 2007. Regulamenta a Lei no 10.831, de 23 de dezembro de 2003, que dispõe sobre a agricultura orgânica, e dá outras providências [cited 2011 nov.]. 
Diário Oficial da República Federativa do Brasil, Brasília, DF, 2007 dez. 28. Available from: http:// www.planalto.gov.br/ccivil_03/_ato2007-2010/2007/ Decreto/D6323.htm.

Brasil. Presidência da República. Casa Civil. Subchefia para Assuntos Jurídicos. Lei no 10.831, de 23 de dezembro de 2003. Dispõe sobre a agricultura orgânica e dá outras providências. [cited 2011 nov.]. Diário Oficial da República Federativa do Brasil, Brasília, DF, 2003 dez. 24. Available from: http://www.planalto.gov. br/ccivil_03/LEIS/2003/L10.831.htm.

87 Schultz G. Agroecologia, agricultura orgânica e institucionalização das relações com o mercado nas organizações de produtores do Sul do Brasil. Agrária 2007; 7:61-93.

88 Azevedo E. AO e suas correntes [cited 2011 nov.]. Portal Orgânico. Available from: http://www. portalorganico.com.br/sub/16/ao_e_suas_correntes

89 Krolow AC, Schwengber J, Ferri N. Avaliações físicas e químicas de morango cv. Aromas produzidos em sistema orgânico e convencional. Revista Brasileira de Agroecologia 2007; 2(2):1732-1735.

90 Martins VA, Camargo Filho WP, Bueno CRF. Preços de frutas e hortaliças da agricultura orgânica no mercado varejistas da cidade de São Paulo. Informações Econômicas 2006; 36(9):42-52.

91 Borguini RG, Torres EAFS. Alimentos orgânicos: qualidade nutritiva e segurança do alimento. Segurança Alimentar e Nutricional 2006; 13(2):64-75.

92 Wan HB, Wong MK. Minimization of solvent consumption in pesticide residue analysis. Journal of Chromatography A 1996; 754:43-47. http://dx.doi. org/10.1016/S0021-9673(96)00537-7

93 Cajka T, Hajslova J, Lacina O, Mastovska K, Lehotay SJ. Rapid analysis of multiple pesticide residues in fruit-based baby food using programmed temperature vaporiser injection-low-pressure gas chromatography-high-resolution time-of-flight mass spectrometry. Journal of Chromatography A 2008; 1186: 281294. PMid:18164024. http://dx.doi. org/10.1016/j.chroma.2007.12.009

94 Lehotay SJ. Determination of pesticide residues in nonfatty foods by supercritical fluid extraction and gas chromatography/mass spectrometry: Collaborative study. Journal of AOAC International 2002; 85(5):11481166. PMid:12374416.

95 Prestes OD, Friggi CA, Adaime MB, Zanella R. QuEChERS - Um método moderno de preparo de amostra para determinação multirresíduo de pesticidas em alimentos por métodos cromatográficos acoplados à espectrometria de massas. Química Nova 2009; 32(6):1620-1634. http://dx.doi.org/10.1590/ S0100-40422009000600046

96 Taylor MJ, Hunter KB, Lindsay D, Le Bouhellec S. Multi-residue method for rapid screening and confirmation of pesticides in crude extracts of fruits and vegetables using isocratic liquid chromatography with electrospray tandem mass spectrometry. Journal of Chromatography A, 2002, 982: 225-236. http:// dx.doi.org/10.1016/S0021-9673(02)01610-2

97 Wilkowska A, Biziuk M. Determination of pesticide residues in food matrices using the QuEChERS methodology. Food Chemistry 2011;125: 803-812. http://dx.doi.org/10.1016/j.foodchem.2010.09.094

98 Schenck FJ, Callery P, Gannett PM, Daft JR, Lehotay SJ. Comparison of magnesium sulfate and sodium sulfate for removal of water from pesticide extracts of foods. Journal of AOAC International 2002; 85(5):1177-1180. PMid:12374418.

99 Anastassiades M, Lehotay SJ, Stajnbaher D, Schenck FJ. Fast and easy multiresidue method employing acetonitrile extraction/partitioning and "Dispersive Solid-Phase Extraction" for the determination of pesticide residues in produce. Journal of $A O A C$ International 2003; 86(2):412-431. PMid:12723926.

100 Jansson C, Pihlström T, Österdahl BG, Markides KE. A new multi-residue method for analysis of pesticide residues in fruit and vegetables using liquid chromatography with tandem mass spectrometric detection. Journal of Chromatography A 2004, 1023:93104. PMid:14760853. http://dx.doi.org/10.1016/j. chroma.2003.10.019

101 Ortelli D, Edder P, Corvi C. Multiresidue analysis of 74 pesticides in fruits and vegetables by liquid chromatography-electrospray-tandem mass spectrometry. Analytica Chimica Acta 2004, 520:33. http://dx.doi.org/10.1016/j.aca.2004.03.037

102 ZamoraT, Pozo OJ, López FJ, Hernández F. Determination of tridemorph and other fungicide residues in fruit samples by liquid chromatographyelectrospray tandem mass spectrometry. Journal of ChromatographyA2004, 1045:137-143.PMid:15378888. http://dx.doi.org/10.1016/j.chroma.2004.06.041

103 Soler C, Mañes J, Pico Y. Liquid chromatographyelectrospray quadrupole ion-trap mass spectrometry of nine pesticides in fruits. Journal of Chromatography 
A 2004, 1048:41-49. PMid:15453417. http://dx.doi. org/10.1016/j.chroma.2004.07.023

104 Falqui-Cao C, Wang Z, Urruty L, Pommier JJ, Montury M. Focused Microwave Assistance for Extracting Some Pesticide Residues from Strawberries into Water before Their Determination by SPME/HPLC/ DAD. Journal of Agricultural and Food Chemistry 2001; 49:5092-5097. PMid:11714287. http://dx.doi. org/10.1021/jf010519u

105 Papadakis EN, Vryzas Z, Papadopoulou-Mourkidou E. Rapid method for the determination of 16 organochlorine pesticides in sesame seeds by microwave-assisted extraction and analysis of extracts by gas chromatography-mass spectrometry. Journal of Chromatography A 2006, 1127(1-2):611. PMid:16797565. http://dx.doi.org/10.1016/j. chroma.2006.06.010

106 Chen L, Ding L, Jin H, Song D, Zhang H, Li J et al. The determination of organochlorine pesticides based on dynamic microwave-assisted extraction coupled with on-line solid-phase extraction of high-performance liquid chromatography. Analytica Chimica Acta 2007; 589(2):239-246. PMid:17418187. http://dx.doi. org/10.1016/j.aca.2007.03.003

107 Nagami H. Multiresidue analysis of fungicides in strawberry. Bulletin Environmental Contamination Toxicology 1997; 58:53-60. PMid:8952925. http:// dx.doi.org/10.1007/s001289900299

108 Albero B, Sánchez-Brunete C, Tadeo JL. Multiresidue determination of pesticides in juice by solid-phase extractionandgaschromatography-massspectrometry. Talanta 2005; 66:917-924. PMid:18970072. http:// dx.doi.org/10.1016/j.talanta.2004.12.046

109 Topuz S, Özhan G, Alpertunga B. Simultaneous determination of various pesticides in fruit juices by HPLC-DAD. Food Control 2005; 16(1):87-92. http:// dx.doi.org/10.1016/j.foodcont.2003.11.012

110 Ceshing S, Hui-Chi C. Simultaneous determination of macrolide pesticides in fruits and vegetables by liquid chromatography. Journal of Food and Drug Analysis 2009; 17(3):198-208.

111 Yang X, Zhang H, Liu Y, Wang J, Zhang YC, Dong AJ et al. Multiresidue method for determination of 88 pesticides in berry fruits using solid-phase extraction and gas chromatography-mass spectrometry: Determination of 88 pesticides in berries using SPE and GC-MS. Food Chemistry 2011; 127(2):855-865. http://dx.doi.org/10.1016/j.foodchem.2011.01.024
112 Hu R, Hennion B, Urruty L, Montury M. Solid phase microextraction of pesticide residues from strawberries. Food Additives and Contaminants 1999; 16(3):111-117. PMid:10492703. http://dx.doi. org/10.1080/026520399284154

113 Lambropoulou DA, Albanis TA. Headspace solidphase microextraction in combination with gas chromatography-mass spectrometry for the rapid screening of organophosphorus insecticide residues in strawberries and cherries. Journal of Chromatography A 2003; 993:197-203. http://dx.doi.org/10.1016/ S0021-9673(03)00397-2

114 Chai MK, Tan GH. Validation of a headspace solid-phase microextraction procedure with gas chromatography-electron capture detection of pesticide residues in fruits and vegetables. Food Chemistry 2009; 117:561. http://dx.doi.org/10.1016/j. foodchem.2009.04.034

115 Liu M, Yuki H, Song Y, Lin J. Determination of Carbamate and Organophosphorus Pesticides in Fruits and Vegetables Using Liquid ChromatographyMass Spectrometry with Dispersive Solid Phase Extraction. Chinese Journal of Analytical Chemistry 2006, 34(7):941-945. http://dx.doi.org/10.1016/ S1872-2040(06)60045-5

116 Radisc M, Grujic S, Vasiljevic T, Lausevic M. Determination of selected pesticides in fruit juices by matrix solid-phase dispersion and liquid chromatography-tandem mass spectrometry. Food Chemistry 2009; 113:712-719. http://dx.doi. org/10.1016/j.foodchem.2008.07.103

117 Haib J, Hofer I, Renaud JM. Analysis of multiple pesticide residues in tobacco using pressurized liquid extraction, automated solid-phase extraction clean-up and gas chromatography-tandem mass spectrometry. Journal of Chromatography A 2003, 1020:173187. PMid:14661742. http://dx.doi.org/10.1016/j. chroma.2003.08.049

118 Tanaka T, Hori T, Asada T, Oikawa K, Kawata K. Simple one-step extraction and cleanup by pressurized liquid extraction for gas chromatographic-mass spectrometric determination of pesticides in green leafy vegetables. Journal of Chromatography A 2007; 1175:181-186. PMid:17996881. http://dx.doi. org/10.1016/j.chroma.2007.10.060

119 Soler C, James KJ, Pico Y. Capabilities of different liquid chromatography tandem mass spectrometry systems in determining pesticide residues in food: Application to estimate their daily intake Journal of 
Chromatography A 2007; 1157:73-84. PMid:17466998. http://dx.doi.org/10.1016/j.chroma.2007.04.009

120 Pat S, Bart T, Frank D. Multi-residue screening of pesticides in vegetables, fruits and baby food by stir bar sorptive extraction-thermal desorption-capillary gas chromatography-mass spectrometry. Journal of Chromatography A 2003; 1000:299-309. http://dx.doi. org/10.1016/S0021-9673(03)00508-9

121 Juan-García A, Mañes J, Font G, Pico Y. Evaluation of solid-phase extraction and stir-bar sorptive extraction for the determination of fungicide residues at low- $\mu \mathrm{g}$ $\mathrm{kg}^{-1}$ levels in grapes by liquid chromatography-mass spectrometry Journal of Chromatography A 2004; 1050(2):119-127. PMid:15508304. http://dx.doi. org/10.1016/j.chroma.2004.08.026

122 Lehotay SJ, Mastovská K, Yun SJ. Evaluation of two fast and easy methods for pesticide residue analysis in fatty food matrixes. Journal of AOAC International 2005; 88(2):630-638. PMid:15859091.

123 Lehotay SJ. Pesticide Analysis in Methods in Biotechnology. Edited by Martínez JL, Martinez V, Frenich AG. Humana Press; 2004.

124 Lehotay SJ, De Kok A, Hiemstra M, Bodegraven P. Validation of a fast and easy method for the determination of 229 pesticide residues in fruits and vegetables using gas and liquid chromatography and mass spectrometric detection. Journal of AOAC International 2005; 88(2):595-614. PMid:15859089.

125 Quick Easy Cheap Effective Rugged Safe - QuEChERS. A Mini-Multiresidue method for the analysis of pesticide residues in low-fat products [cited 2011 sept.]. QuEChERS; 2011. Available from: http://www. quechers.com/

126 Lehotay SJ, Son KA, Kwon H, Koesukwiwat U, Fu W, Mastovska K et al. Comparison of QuEChERS sample preparation methods for the analysis of pesticide residues in fruits and vegetables. Journal of Chromatography A 2010, 1217:25482560. PMid:20144460. http://dx.doi.org/10.1016/j. chroma.2010.01.044

127 Lehotay SJ, Anastassiades M, Majors RE. QuEChERS, a sample preparation technique that is "Catching On": An up-to-date interview with the inventors. LCGC North America 2010; 28(7):504-516.

128 Lehotay SJ, Mastovská, K, Lightfield, AR. Use of buffering and other means to improve results of problematic pesticides in a fast and easy method for residue analysis of fruits and vegetables.
Journal of AOAC International 2005;88(2):615-629. PMid:15859090.

129 Lanças FM. Extração em Fase Sólida - SPE. São Carlos: Editora Rima; 2004.

130 Prestes OD, Adaime, MB, Zanella R. QuEChERS: possibilidades e tendências no preparo de amostra para determinação multirresíduo de pesticidas em alimentos. Scientia Chromatographica 2011; 3:51-64. http://dx.doi.org/10.4322/sc.2011.004

131 Torres CM, Pico Y, Manes J. Determination of pesticide residues in fruit and vegetables. Journal of Chromatography A 1996; 754: 301-331. http://dx.doi. org/10.1016/S0021-9673(96)00407-4

132 Vidal JLM, Arrebola FJ, Sánchez MM. Application of gas chromatography-tandem mass spectrometry to the analysis of pesticides in fruits and vegetables. Journal of Chromatography A 2002; 959:203-213. http://dx.doi.org/10.1016/S0021-9673(02)00444-2

133 Blasco C, Fernández M, Pico Y, Font G, Mañes J. Simultaneous determination of imidacloprid, carbendazim, methiocarb and hexythiazox in peaches and nectarines by liquid chromatographymass spectrometry. Analytica Chimica Acta 2002; 461:109-116. http://dx.doi.org/10.1016/S00032670(02)00255-6

134 Hiemstra M, Kok A. Comprehensive multiresidue method for the target analysis of pesticides in crops using liquid chromatography-tandem mass spectrometry. Journal of Chromatography A 2007; 1154:3-25. PMid:17442324. http://dx.doi. org/10.1016/j.chroma.2007.03.123

135 Lanças FM. Cromatografia Líquida Moderna. Campinas: Editora Átomo; 2009.

136 Lanças FM. A cromatografia líquida moderna e a espectrometria de massas: finalmente "compatíveis"? Scientia Chromatographica 2009; 1(2):35-61.

137 Meyer VR. Practical High Performance Liquid Chromatography.4rd@\#@ed. Local: John Wiley \& Sons; 2004.

138 Collins CH, Braga GL, Bonato PS. Fundamentos de Cromatografia. Campinas: Editora da UNICAMP; 2006.

139 Holler FJ, Skoog DA, Crounch SR. Princípios de Análise Instrumental.6rd@\#@ed. Porto Alegre: Editora Bookman; 2009.

140 Abad A, Moreno MJ, Pelegrı R, Martinez MI, Saez A, Gamon $\mathrm{M}$ et al. Determination of carbaryl, 
carbofuran and methiocarb in cucumbers and strawberries by monoclonal enzyme immunoassays and high-performance liquid chromatography with fluorescence detection: An analytical comparison. Journal of Chromatography A 1999; 833:3-12. http:// dx.doi.org/10.1016/S0021-9673(98)00856-5

141 MalikAK,BlascoC,Pico Y.Liquidchromatography-mass spectrometry in food safety. Journal of Chromatography A 2010, 1217:4018-4040. PMid:20392451. http://dx.doi. org/10.1016/j.chroma.2010.03.015

142 Hajslova J, Zrostlıkova J. Matrix effects in (ultra) trace analysis of pesticide residues in food and biotic matrices. Journal of Chromatography A 2003, 1000:181-197. http://dx.doi.org/10.1016/S0021-9673 (03)00539-9

143 Vekey K. Mass spectrometry and mass-selective detection in chromatography. Journal of Chromatography A 2001; 921:227. http://dx.doi. org/10.1016/S0021-9673(01)00825-1

144 Fernandez M, Rodriguez R, Pico Y, Manes J. Liquid chromatographic-mass spectrometric determination of post-harvest fungicides in citrus fruits. Journal of Chromatography A 2001; 912:301-310. PMid:11330799. http://dx.doi.org/10.1016/S00219673(01)00576-3

145 Frenich AG, Vidal JLM, López-López T, Cortés AS, Martínez IS. Monitoring multi-class pesticide residues in fresh fruits and vegetables by liquid chromatography with tandem mass spectrometry. Journal of Chromatography A 2004; 1048:199206. PMid:15481257. http://dx.doi.org/10.1016/j. chroma.2004.07.027

146 García-Reyes JF, Ferrer C, Gómez-Ramos MJ, MolinaDíaz A, Fernández AAR. Determination of pesticide residues in olive oil and olives. Trends in Analytical Chemistry 2007; 26(3):239-251. http://dx.doi. org/10.1016/j.trac.2007.01.004

147 Chiaradia MC, Collins CH, Jardim ICSF. O estado da arte da cromatografia associada à espectrometria de massas acoplada à espectrometria de massas na análise de compostos tóxicos em alimentos. Química. Nova 2008; 31(3):623. http://dx.doi.org/10.1590/ S0100-40422008000300030

148 Fernández-Alba AR, García-Reyes JF. Large-scale multi-residue methods for pesticides and their degradation products in food by advanced LC-MS. Trends in Analytical Chemistry 2008; 27(11):973-990. http://dx.doi.org/10.1016/j.trac.2008.09.009

149 Pihlström T. Method validation and quality control procedures for pesticides residues analysis in food and feed. National Food Administration; 2008. Document $\mathrm{n}^{\circ}$ SANCO/10684/2009. Supersedes Document $\mathrm{n}^{\circ}$ SANCO/3131/2007. Implementado em 01/01/2010.

150 Urruty L, Montury M. SPME and pesticide residues in food analysis. Application to strawberries. Revue. F. S. B. $2002 ; 1: 5-11$.

151 Sagratini A, Mañes J, Giardiná D, Damiani P, Pico Y. Analysis of carbamate and phenylurea pesticide residues in fruit juices by solid-phase microextraction and liquid chromatography-mass spectrometry. Journal of Chromatography A 2007, 1147:135143. PMid:17362971. http://dx.doi.org/10.1016/j. chroma.2007.02.066

152 Montero TM, Moll EM, Esteban RM, López-Andréu FJ. Quality attributes of strawberry during ripening. Scientia Horticulturae 1996; 65:239-250. http://dx.doi. org/10.1016/0304-4238(96)00892-8

153 Mangas JJ, Moreno J, Suárez B, Picinelli A, Blanco D. Liquid chromatographic analysis of non-volatile strawberry compounds. Chromatographia 1998, 47(34):197-202. http://dx.doi.org/10.1007/BF02466581

154 Herrera MC, Castro MDL. Ultrasound-assisted extraction for the analysis of phenolic compounds in strawberries. Analytical Bioanalytical Chemistry 2004; 379:1106-1112. PMid:15221196. http://dx.doi. org/10.1007/s00216-004-2684-0

155 Silva FL, Escribano-Bailon MT, Alonso JJP, RivasGonzalo JC, Santos-Buelga C. Anthocyanin pigments in strawberry. LWT 2007; 40:374. http://dx.doi. org/10.1016/j.lwt.2005.09.018

Recebido: 09/03/2012

Aceito: 16/03/2012 